\title{
Exposure of the hands to ionizing radiation in the resuscitation room of an accident \& emergency department
}

\author{
R. J. EVANS, S. CUSACK \& T. PARKE \\ Accident \& Emergency Department, Royal Infirmary, Lauriston Place, Edinburgh
}

\section{SUMMARY}

Exposure of the hands to ionizing radiation in the resuscitation room of an A\&E department was measured in eight health care personnel over 3 consecutive months. The radiation levels did not exceed those limits currently recommended by the International Commission on Radiological Protection 1990. The level recorded in one individual did exceed the level set at the Lothian Health Boards investigation limit.

In only five of 85 occasions were lead gloves worn by the doctor during cross table lateral cervical radiographs.

Recommendations are made for reducing the radiation exposure to the hands.

\section{INTRODUCTION}

A\&E Department personnel experience potential occupational exposure to ionizing radiation in the resuscitation room. A 9-year evaluation of A\&E department personnel using standard film dosemeter badges concluded the risk to be minimal and that routine monitoring was unnecessary if standard radiation precautions are taken (Grazer et al., 1987). This was supported in a study which measured radiation at varying distances from the edge of an irradiated field during portable cross table cervical spine, chest and pelvic radiographs using a phantom trauma model. They concluded the risk to be minimal if the protective lead apron was worn or one stood $40 \mathrm{~cm}$ away from the primary beam in the cases of the chest and cervical radiographs and at a distance of $160 \mathrm{~cm}$ in the case of the pelvic radiographs (Grazer et al. April, 1987).

Correspondence: Mr. R. J. Evans, Senior Registrar in Accident \& Entergency Medicine, Cardiff Royal Infirmary, Cardiff, South Glamorgan, Wales. 
Trauma patients require cervical spine immobilization until clinical and, if required, radiographic evidence has excluded cervical spine injury. In the department this is generally achieved by the team leader who supports the patients head to prevent cervical movement whilst a lateral cross table cervical spine radiograph is performed.

In the department all members present in the resuscitation room during the taking of radiographs wear protective lead aprons or stand behind a lead shield. The use of protective lead gloves is infrequently adopted.

The purpose of our study was to determine the radiation exposure of the hands of $A \& E$ staff during 3 consecutive months.

\section{MATERIALS AND METHODS}

For 3 consecutive months seven doctors and a nurse wore finger stalls on each ring finger when they attended patients in the resuscitation room. A record was made of radiographs performed during the resuscitation, the individuals present who had finger stalls, the details of the doctor who supported the cervical spine during radiography and whether lead gloves were worn and the number of repeat radiographs.

The finger stalls were thermoluminescent dosemeters containing a thin layer of lithium fluoride powder within a sealed pocket in the stall. Each subject retained the finger stalls for a calendar month after which they were sent for analysis to the National Radiological Protection Board.

\section{RESULTS}

Over 3 months 143 patients required emergency radiography in the resuscitation room. A total of 790 examinations were made including 163 chest; 158 skull; 91 cervical; 73 pelvic; 53 lumbar spine; 41 thoracic spine; 211 extremity and miscellaneous radiographs.

The individual's exposure to the various radiographs, and in particular the number of cross table lateral cervical spine radiographs when supporting the cervical spine, are shown in Table 1.

The cumulative exposure to the right and left hand over the 3-month period with the number of occasions when lead gloves were worn is shown in Table 2.

Thirty-two (4\%) of radiographs were repeated.

\section{DISCUSSION}

$X$-ray exposure arises from the main X-ray beam or from secondary radiation scatter from the patient. Within the main beam the $X$-ray intensity is governed by 
Table 1. Distribution of radiographs.

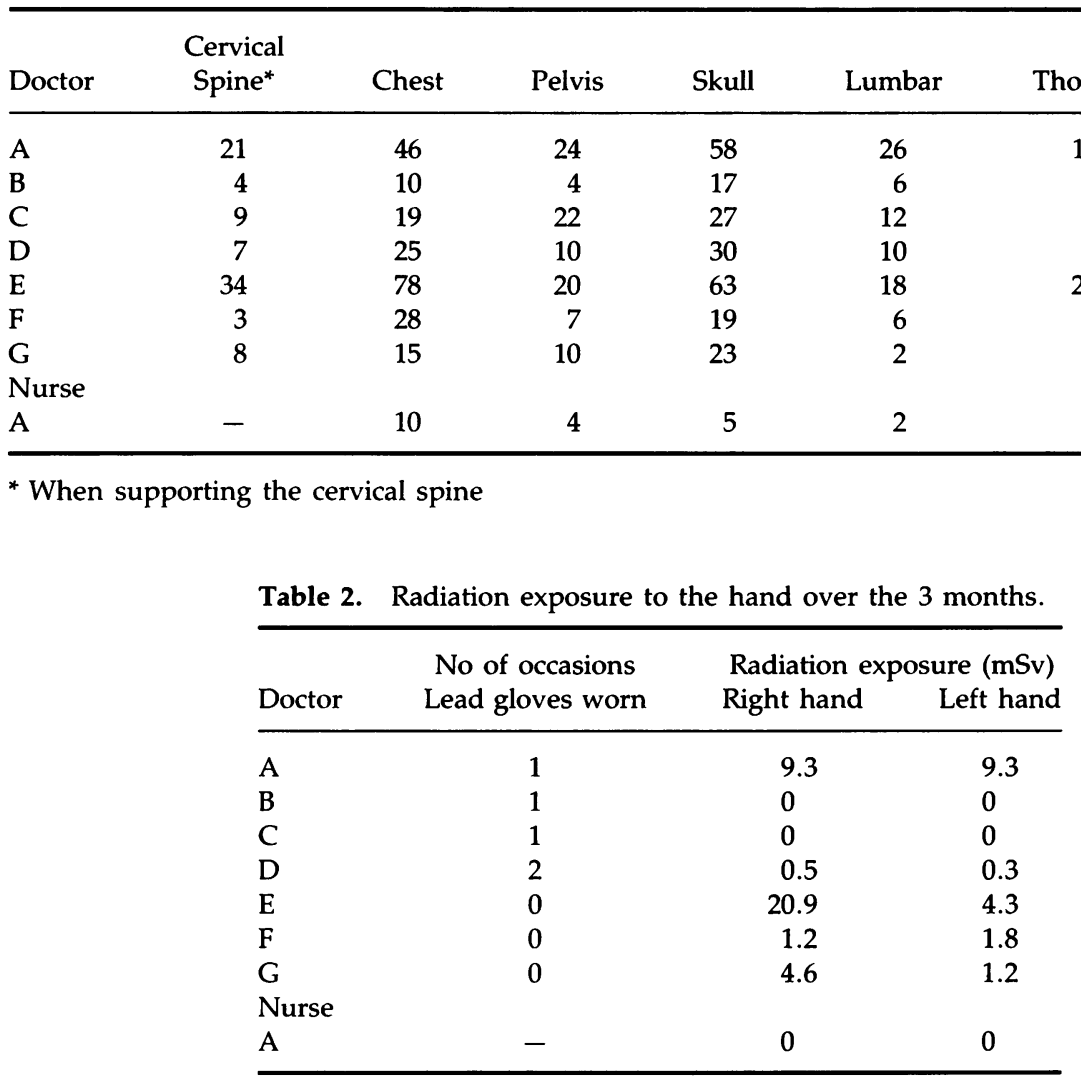

the inverse square law, hence the benefit from maintaining as much distance as possible from the source.

The radiation hazard to staff is a function of the overall design of the $\mathrm{X}$-ray equipment, working methods and workload. In the resuscitation room the X-ray tube is positioned above the patient - an overcouch tube. Measurements of the scattered radiation at the patients side, have shown it is increased compared to that of an undercouch tube. (Faulkner \& Moores, 1982). This necessitates the use of a lead rubber apron to reduce the whole-body dose. But there still exists the potential exposure to the eyes, thyroid and extremities.

In the A\&E department the risk to the hands is mostly related to the exposure during manual cervical stabilization when performing a cross table lateral cervical spine radiograph. This risk has been shown to be reduced by $99.9 \%$ by wearing $0.5 \mathrm{~mm}$ lead-equivalent gloves (Singer et al., 1989). Unfortunately this practice was adopted on only five occasions in our study.

Published guide-lines for reducing medical $X$-ray exposure cover the issues of inappropriate indications for radiographs, inadequate or faulty equipment, the shielding of the body and the substitution of ultrasound or other diagnostic methods when appropriate (Boice, 1986). 
Table 3. Dose limits (mSv).

\begin{tabular}{lrrrrr}
\hline & A & B & C & D & E \\
\hline Whole body & 50 & 5 & 15 & 5 & 20 \\
Lens of the eye & 150 & 15 & 45 & 20 & 150 \\
Thyroid & 500 & 50 & 150 & 20 & - \\
Extremities & 500 & 50 & 150 & 50 & 500 \\
Foetus* & 10 & - & - & 1 & 5 \\
\hline
\end{tabular}

* Dose received during the full term pregnancy of an occupationally exposed worker.

A Current legal limit for occupationally exposed workers

B Current legal limit to members of the general public

C Classification limit

D Lothian Health Boards investigation limit

E Limit proposed by the ICRP in a draft report (1990)

Repeat films are another contributing factor to excess X-ray and in our study we had a repeat rate of only $4 \%$ which compares well with the rate of $10 \%$ previously found in a study between 18 radiology departments (De Lacey, 1987).

A variety of dose limits have been summarized in the table above (Table 3 ).

In our study not one individual exceeded the currently recommended limit of $500 \mathrm{mSv}$ year ${ }^{-1}$ of the International Commission on Radiological Protection (ICRP) 1990. The Lothian Health Boards limit of $50 \mathrm{mSv}_{\text {year }}{ }^{-1}$ would have been exceeded by doctor $E$ if his level of $20.9 \mathrm{mSv}$ year $^{-1}$ over the 3-month period was continued.

It should be noted that the concept of ALARA (As Low As Reasonably Achievable) as stressed at the Conference on Radiation Protection and Dosemetry (Sims et al., 1989) should be adopted and the Radiation Adviser after review of the departments practises advised the importance of protecting the extremities by the practical step of wearing lead gloves during cross table lateral cervical spine radiographs in the resuscitation room and at a later date a repeat study will be conducted to assess the exposure to the hands.

\section{ACKNOWLEDGEMENTS}

We are grateful to Dr K. Little for permission to perform the study. We also thank the radiographers who assisted in the study. We are finally grateful to Mr J. R. Williams of the Medical Physics Department for his assistance.

\section{REFERENCES}

Boice, J. D. (1986) The danger of X-rays - real or apparent. The Nerw England Journal of Medicine. 315(13), 828-830.

Faulkner, K. \& Moores, B. M. (1982) An assessment of the radiation dose received by staff using fluoroscopic equipment. British Journal of Radiology, 55, 272-276. 
Grazer, R. E., Meislin, H. W., Westerman, B. R. \& Criss, E. A. (1987) A nine-year evaluation of emergency department personnel exposure to ionizing radiation. Annals of Emergency Medicine 16, $340-342$.

Lacey G. de. (1987) Over-exposure to radiology. British Medical Journal. 295, 1162-1163.

Sims, C. S. \& Swaja, R. E. (1989) Summary statements from the second conference on radiation protection and dosimetry. Health Physics 57(3), 461-463.

Singer, C. M., Baraff, L. J., Benedict, S. H., Weiss, E. L. \& Singer, B. D. (1989) Exposure of emergency medical personnel to ionizing radiation during cervical spine radiography. Annals of Emergency Medicine 18(8), 822-825. 